\title{
Intrathecal Bupivacaine as Monotherapy for Non-Malignant Chronic Pain: A Case Series
}

\author{
Jason Hale ${ }^{1}$, Elizabeth Casserly ${ }^{2 *}$ and Jianguo Cheng ${ }^{1,3}$
}

${ }^{1}$ Deptartment of Pain Management, Cleveland Clinic Foundation, Cleveland, $\mathrm{OH}, \mathrm{USA}$

${ }^{2}$ Department of Pharmacy, Cleveland Clinic Foundation, Cleveland, OH, USA

${ }^{3}$ Deptartment of Neurosciences, Cleveland Clinic Foundation, Lerner Research Institute, Cleveland, OH, USA

\begin{abstract}
Chronic, non-malignant pain can be particularly challenging to treat. Patients who are resistant to medications, nerve blocks, and spinal cord stimulators may eventually receive intrathecal therapy. Opioids are often first line medications for intrathecal therapy, but they frequently cause unacceptable side effects or become ineffective due to tolerance. This is particularly problematic in non-cancer pain, as these patients often require ongoing pain management for decades. Fortunately, combining opioids with other intrathecal medications, such as bupivacaine, clonidine, or ziconotide is very common and often produces improved analgesia. Some patients, however, have persistent pain despite first line or combination therapy, and these patients can be particularly difficult to manage. Bupivacaine is well documented as an excellent adjunct medication in intrathecal therapy, but there is little evidence supporting its use as monotherapy. We reviewed four non-cancer chronic pain patients who failed opioid or ziconotide intrathecal therapy and ultimately were placed on intrathecal bupivacaine as monotherapy. Their clinical courses and pain control are presented based on thorough review of their medical records. Three of our four patients have, at present, achieved effective analgesia with intrathecal bupivacaine monotherapy. This report is limited by the small number of patients as well as the known limitations of retrospective study. However, these data suggest that that pain physicians may consider intrathecal bupivacaine as monotherapy in patients who have failed to respond to other treatment regimens.
\end{abstract}

Keywords: Monotherapy; Drugs; Hydromorphone; Pain management

\section{Introduction}

Intrathecal drug therapy is a well-known practice in the management of chronic pain patients. Patients with chronic pain, both malignant and nonmalignant, who have not achieved adequate pain relief from a multitude of interventions are often considered for intrathecal pumps. Medication is delivered to the spinal cord on a continuous basis in an outpatient setting through an implanted reservoir pump and catheter. The most common medications in this setting include opioids, local anesthetics, clonidine, and ziconotide.

Opioid medications, particularly the more hydrophilic drugs morphine and hydromorphone, are used frequently as first-line agents in patients with intrathecal pumps who have either cancer-related or nociceptive chronic pain [1]. While opioids are effective at treating nociceptive pain, they are less effective in treating neuropathic pain [2]. Intrathecal opioids are wrought with common side effects such as hyperalgesia, urinary retention, pruritis, constipation, decreased libido, hypogonadism and other various endocrine disorders, psychological dependence, tolerance, and respiratory depression $[1,3]$. Furthermore, opioid tolerance often leads to frequent dose increases in patients who are treated for long periods of time, leading to ineffective analgesia at high doses [2,4].

Ziconotide is an intrathecal therapy that works as a calcium channel blocker [1]. This medication is commonly used for neuropathic pain and is not available in an oral form. The drawbacks of this medication, however, include its high cost and narrow therapeutic index. Some patients cannot tolerate the mediation at all because of common side effects of dizziness, nausea, vomiting, and hypotension. Patients need to be monitored when starting ziconotide as it can increase creatine phosphokinase. Ziconotide should not be used in patients with a history of psychosis as it can provoke an exacerbation. As many as $31 \%$ of patients treated with ziconotide will have side effects [3-6].
A third medication commonly used for intrathecal therapy includes the lipid soluble local anesthetic bupivacaine, which is the focus of this case series. Bupivacaine is shown to be an effective adjunct intrathecal medication when added to a regimen of intrathecal opioids $[1,3,7,8]$. Bupivacaine reduces dose escalations of intrathecal opioids, and it even allows some patients to reduce their oral opioid use $[9,10]$. Side effects are relatively uncommon and include motor weakness, paresthesias, urinary incontinence, and hypotension [11].

Though many non-malignant chronic pain patients have effective analgesia with opioids, ziconotide, and/or bupivacaine, some patients with intrathecal pumps present significant challenges in pain management. Either decreased efficacy of medications over time or intolerable side effects with dose escalations can leave patients with ineffective analgesia. We present four cases of challenging non-malignant patients who ultimately ended up with intrathecal bupivacaine as monotherapy, a pain management regimen that has scarcely has been reported in the literature.

\section{Methods}

All patients currently seen in our pain management center who are receiving intrathecal bupivacaine monotherapy, or who had at one point received intrathecal bupivacaine monotherapy, were

*Corresponding author: Elizabeth Casserly, Department of Pharmacy, Cleveland Clinic Foundation, Cleveland, OH, USA, Tel: 8002232273; E-mail: cassere@ccf.org

Received March 26, 2018; Accepted April 07, 2018; Published April 12, 2018

Citation: Hale J, et al. (2018) Intrathecal Bupivacaine as Monotherapy for NonMalignant Chronic Pain: A Case Series. J Trauma Treat 6: 422. doi: 10.4172/21671222.1000422

Copyright: (c) 2018 Hale J, et al. This is an open-access article distributed under the terms of the Creative Commons Attribution License, which permits unrestricted use, distribution, and reproduction in any medium, provided the original author and source are credited. 
identified and included. Four such patients were identified, and their clinical courses are detailed below based on a thorough review of their medical records. Pain control was evaluated based on subjective patient reporting and visual analog scale pain scores at office appointments.

\section{Patient Cases}

The first patient is a 71-year-old male who initially had symptoms of chronic burning pain with significant allodynia to light touch in the lower extremities since his mid-50s. A skin biopsy was consistent with idiopathic peripheral neuropathy. His other medical problems include hypertension, hyperlipidemia, and hypothyroidism. His pain was primarily located over the soles of both feet, and the pain would interfere with sleep. A few years following the onset of these symptoms, he experienced the same burning pain and allodynia in the $4^{\text {th }}$ a $5^{\text {th }}$ digits of both hands, though these symptoms were less severe. Trials of several oral medications included opioids, oxcarbazapine, amitriptyline, gabapentin, topiramate, and NSAIDs without success. Due to lack of efficacy of oral medications, he was eventually referred for a spinal cord stimulator (SCS), which he had for five years but was explanted for lack of efficacy. He further underwent lumbar sympathetic blocks with no relief. After having his SCS removed, he had an intrathecal pump placed and he was started on a regimen of ziconotide, which subjectively mildly improved his symptoms. He continued to rate his pain at outpatient appointments as 5-7/10 on the visual analog scale (VAS). He eventually developed symptoms of auditory hallucinations and confusion at a dose of $2 \mathrm{mcg} /$ day. He was subsequently switched to intrathecal morphine. Morphine provided some relief. He rated his pain $5 / 10$ with $500 \mathrm{mcg} /$ day but suffered from cognitive side effects. The subsequent addition of bupivacaine did not provide any significant relief. As part of a chronic rehabilitation program to discontinue the use of all opioids, he was weaned off morphine. According to the patient, discontinuing all opioid medications improved his functional status and quality of life. Initial intrathecal bupivacaine monotherapy seemed ineffective, but he began to report relief with dose increases. He was on intrathecal bupivacaine $7 \mathrm{mg}$ /day for about one year with VAS scores in the clinic of $4 / 10$ or less. His oral medications during this time were gabapentin and meloxicam. During some visits, he reported his pain at $0 / 10$, though it was unclear if his pain relief was from bupivacaine. Decreasing doses did not seem to subjectively worsen his pain, and dose increases did not seem to improve his pain. As the device was nearing end of life, the patient decided to have the pump explanted, as it was not believed to be providing any benefit. His dose was titrated down and there appeared to be no worsening of his pain. About one week after device explant, the patient returned to clinic and rated his pain $2 / 10$. He continues to take meloxicam and gabapentin. He has not yet been seen again in pain management clinic.

The second patient is a 57 -year-old female who presented with stocking distribution of burning, sharp, and stinging pain in both feet and ankles. A nerve biopsy and was consistent with small fiber peripheral sensory neuropathy. Her pain was constant and ranged from $5 / 10$ to $10 / 10$. She had similar symptoms in both hands, but the symptoms were significantly worse in the lower extremities. Her other medical problems include depression, anxiety, and hypothyroidism. Medical management included tramadol, oxycontin, acetaminophenhydrocodone, lidocaine patches, capsaicin cream, gabapentin, pregabalin and a transcutaneous electrical nerve stimulation unit with limited success. A series of three lumbar sympathetic blocks provided about $30 \%$ relief for a duration of about two weeks each. She had a successful spinal cord stimulator trial but was reluctant to have a permanent device implanted. An intrathecal trial with hydromorphone was performed with good response. She underwent a permanent pump implant and was started on intrathecal hydromorphone. This provided good pain relief, but she required dose increases for continued efficacy. After approximately four months, her pain was not well controlled, and her pain was rated $7 / 10$ with $3.435 \mathrm{mg} /$ day of hydromorphone. The addition of bupivacaine to hydromorphone initially achieved complete analgesia with a pain score of $0 / 10$. At subsequent visits, however, she had various pain scores ranging from $3-8 / 10$. Overall, the patient felt that the addition of bupivacaine was very helpful in controlling her neuropathic pain. Unfortunately, the hydromorphone caused unwanted side effects including significant weight gain, back pain, limited mobility, and recurrent pneumonias. The patient desired to discontinue intrathecal and oral opioids. Her intrathecal hydromorphone was weaned down and eventually discontinued without any appreciable worsening of her pain. Her oral opioid medications were weaned successfully as well. Her activity level subsequently improved, and she overall felt better off opioids. Her current pain management regimen, which reportedly provides satisfactory analgesia, now consists of intrathecal bupivacaine $2.4 \mathrm{mg} /$ day, buprenorphine patch, lidocaine patch, and lidocaine cream. Her pain scale continues to vary significantly but is around 5-6/10 when she is not having an exacerbation. It is unclear which therapy from her current regimen is most effective, but each medication is currently felt to have some efficacy.

The third patient is a 48-year-old female with chronic interstitial cystitis and chronic pelvic pain since the age of 18. Extensive gynecology and genitourinary evaluations with multiple laparoscopic surgeries were unrevealing. Her other medical problems include vertigo and acid reflux. At an outside pain management clinic, she had pudendal nerve blocks, hypogastric plexus blocks, ganglion impar blocks, and she eventually underwent implantation of an intrathecal pump. The patient failed ziconotide therapy due to auditory hallucinations while her pump was managed at the outside clinic. She was then switched to bupivacaine monotherapy. She subsequently presented to our clinic, and she rated her pain at this time as $7 / 10$, with a range of $4-10 / 10$. Her pain was worsened with activity and improved with pudendal nerve blocks, heating pads, ice, laying down and physical therapy. Her participation in physical therapy was limited due to her chronic headaches. Review of her outside records does not indicate that she ever received intrathecal opioids. She initially required revision for an inverted pump when she came to our department, and she was then restarted on bupivacaine $3 \mathrm{mg} /$ day. Her dose was gradually increased up to a maximum dose of $9 \mathrm{mg} /$ day, and she rated her pain at 4-5/10 during office visits. According to the patient, her pelvic pain is now tolerable at this dose. Her only side effect is an intermittent sensation of coldness over both thighs, which the patient believes is unrelated to intrathecal bupivacaine bolus doses. She has since been able to return to work as a professor.

The final patient is a 51-year-old male with a history of hepatitis C and lower extremity weakness and sensory loss secondary to an episode of transverse myelitis at the age of 16 . He is wheelchair bound but does not have full paralysis of his lower extremities. He does have some patchy sensation in his legs. His primary complaint was diffuse skeletal pain from head to toe that developed gradually over 10 years ago. The pain progressed such that it significantly disrupted sleep and daily life. His pain was constant and diffuse over his entire body. It was described as aching, pressure-like, sharp, and stabbing and was rated $10 / 10$. His medical management included morphine, tiagabine, acetaminophenhydrocodone, duloxetine, and oxymorphone. An intravenous lidocaine infusion improved the pain from $8 / 10$ to $0 / 10$, which lasted several 


\begin{tabular}{|c|c|c|c|c|c|c|c|}
\hline $\begin{array}{c}\text { Age } \\
\text { (years) }\end{array}$ & Gender & Diagnosis & $\begin{array}{l}\text { Indication for } \\
\text { intrathecal therapy }\end{array}$ & $\begin{array}{l}\text { Failed oral pain } \\
\text { medications }\end{array}$ & $\begin{array}{c}\text { Reason for intrathecal } \\
\text { bupivacaine monotherapy }\end{array}$ & $\begin{array}{l}\text { Outcome of bupivacaine } \\
\text { monotherapy }\end{array}$ & $\begin{array}{c}\text { Current } \\
\text { additional pain } \\
\text { medications }\end{array}$ \\
\hline 71 & Male & $\begin{array}{l}\text { Idiopathic small } \\
\text { fiber neuropathy }\end{array}$ & $\begin{array}{c}\text { Ineffective analgesia } \\
\text { from oral medications, } \\
\text { spinal cord stimulator, } \\
\text { and lumbar } \\
\text { sympathetic blocks. }\end{array}$ & $\begin{array}{c}\text { Various opioids, } \\
\text { oxcarbazapine, } \\
\text { amitriptyline, } \\
\text { gabapentin, topiramate, } \\
\text { NSAIDs }\end{array}$ & $\begin{array}{l}\text { Ziconotidewas ineffective } \\
\text { and caused hallucinations. } \\
\text { Morphine caused cognitive } \\
\text { side effects, limiting dose } \\
\text { escalation. All opioids were } \\
\text { discontinued through a } \\
\text { rehabilitation program. }\end{array}$ & $\begin{array}{l}\text { Was not particularly } \\
\text { efficaciouseven with dose } \\
\text { escalation upto } 7 \mathrm{mg} / \text { day. } \\
\text { Numbness prevented further } \\
\text { dose increase. Pump was } \\
\text { explanted at end of life. }\end{array}$ & $\begin{array}{l}\text { Meloxicam, } \\
\text { gabapentin }\end{array}$ \\
\hline 57 & Female & $\begin{array}{l}\text { Idiopathic small } \\
\text { fiber neuropathy }\end{array}$ & $\begin{array}{c}\text { Ineffective analgesia } \\
\text { from oral medications, } \\
\text { transcutaneous } \\
\text { electrical nerve } \\
\text { stimulation, and } \\
\text { lumbar sympathetic } \\
\text { blocks. }\end{array}$ & $\begin{array}{c}\text { tramadol, oxycontin, } \\
\text { acetaminophen- } \\
\text { hydrocodone, } \\
\text { anticonvulsants, tricydic } \\
\text { antidepressants, } \\
\text { gabapentin, pregabalin, } \\
\text { duloxetine }\end{array}$ & $\begin{array}{c}\text { Severe weight gain, } \\
\text { back pain, inactivity, and } \\
\text { respiratory complications } \\
\text { from intrathecal } \\
\text { hydromorphone. Patient } \\
\text { desired to discontinue all } \\
\text { opioids. }\end{array}$ & $\begin{array}{l}\text { Overall satisfactory analgesia } \\
\text { with daily dose of } 2.4 \mathrm{mg} / \text { day. }\end{array}$ & $\begin{array}{l}\text { Buprenorphine } \\
\text { patch, lidocaine } \\
\text { patch and cream }\end{array}$ \\
\hline 48 & Female & $\begin{array}{l}\text { Chronic pelvic pain, } \\
\text { medications, } \\
\text { pudendal nerve } \\
\text { interstitial } \\
\text { blocks, hypogastric } \\
\text { plexus blocks, } \\
\text { cystitis } \\
\text { and ganglion impar } \\
\text { blocics. }\end{array}$ & $\begin{array}{l}\text { Ineffective analgesia } \\
\text { from oral }\end{array}$ & unknown & $\begin{array}{c}\text { Ziconotide caused } \\
\text { hallucinations. Patient has } \\
\text { never received intrathecal } \\
\text { opioids. }\end{array}$ & $\begin{array}{c}\text { Overall satisfactory analgesia } \\
\text { with daily dose of } 9 \mathrm{mg} / \mathrm{day} .\end{array}$ & $\begin{array}{l}\text { Topiramate, } \\
\text { gabapentin }\end{array}$ \\
\hline 51 & Female & Diffuse skeletal pain & $\begin{array}{l}\text { Ineffective analgesia } \\
\text { from oral medications }\end{array}$ & $\begin{array}{l}\text { morphine, tiagabine, } \\
\text { acetaminophen- } \\
\text { hydrocodone, } \\
\text { duloxetine, } \\
\text { oxymorphone, } \\
\text { diazepam }\end{array}$ & $\begin{array}{l}\text { Ziconotide was helpful for } \\
\text { many years but eventually } \\
\text { lost efficacy. Intrathecal } \\
\text { hydromorphone was not } \\
\text { helpful and was discontinued. }\end{array}$ & $\begin{array}{c}\text { He achieved satisfactory } \\
\text { analgesia for about } 1 \text { year } \\
\text { with } 1.65 \mathrm{mg} / \text { day. He is } \\
\text { currently undergoing dose } \\
\text { escalation. }\end{array}$ & $\begin{array}{l}\text { Acetaminophen- } \\
\text { oxycodone, } \\
\text { nefazodone, } \\
\text { alprazolam, } \\
\text { tizanidine }\end{array}$ \\
\hline
\end{tabular}

Table 1: Summary of patients including relevant pain management specifics.

hours. He then underwent a ziconotide trial with subsequent intrathecal pump implantation. His "nerve pain" was rated $0 / 10$ with ziconotide $2 \mathrm{mcg} /$ day. His "bone pain" was not as well controlled with ratings of 4-6/10. After doing relatively well for many years with intrathecal ziconotide, his overall pain control eventually became inadequate. The addition of intrathecal hydromorphone did not help and was discontinued. He had several increases in his ziconotide dose without relief. Due to issues with cost as well as decreasing efficacy, the patient wanted to stop ziconotide. He was switched to intrathecal bupivacaine monotherapy. After starting bupivacaine $1.5 \mathrm{mg} /$ day, the patient rated his pain 5/10 and reported a significant improvement in his pain control and quality of life. He was able to decrease his oral opioid dose. His "nerve pain" did not worsen with stopping the ziconotide, and the bupivacaine reportedly was very helpful in controlling his "bone pain." His intrathecal bupivacaine dose was slightly increased to 1.65 $\mathrm{mg} / \mathrm{day}$, and he has continued to rate his pain as tolerable at $5 / 10$. He then had satisfactory pain relief for about one year, and his current oral medications now include acetaminophen-oxycodone, and tizanidine. Most recently, the patient felt like his pain was slightly worsening and he is currently undergoing bupivacaine dose increases.

A table summarizing each patient is provided in Table 1.

\section{Discussion}

Our four cases are challenging patients with non-malignant chronic neuropathic pain. The first patient with idiopathic small fiber neuropathy failed ziconotide and morphine therapy, and he appeared to have some amount benefit with bupivacaine $7 \mathrm{mg} /$ day monotherapy, at least initially. Stopping all opioids was helpful, though the long-term efficacy of bupivacaine was questionable. The second patient also had small fiber neuropathy, and she initially required significant dose increases of her intrathecal hydromorphone. Eventual discontinuation of her intrathecal and oral opioids was beneficial, and she subjectively has satisfactory analgesia with intrathecal bupivacaine $2.4 \mathrm{mg} /$ day when used with other transdermal medications. The third patient has chronic pelvic pain with interstitial cystitis listed in her chart as a diagnosis of exclusion. She never received intrathecal opioids and failed ziconotide therapy. She subjectively reports effective analgesia with intrathecal bupivacaine monotherapy at $9 \mathrm{mg} / \mathrm{day}$, and she has been able to return to work. The final patient has severe diffuse skeletal pain, no definitive diagnosis, and presumably suffers from neuropathic pain. Intrathecal hydromorphone was of no benefit and he failed ziconotide therapy. Intrathecal bupivacaine monotherapy seems effective with only a small dose of $1.65 \mathrm{mg} /$ day achieving adequate analgesia.

In the literature, there is one case report detailing the successful treatment of complex regional pain syndrome (CRPS) with intrathecal bupivacaine monotherapy (maximum daily dose of $21.5 \mathrm{mg}$ ) delivered at the appropriate spinal level [12]. There is also an older, three-patient case series from 1999 describing successful analgesia for CRPS with temporary bupivacaine monotherapy (maximum daily doses of 66, 80 , and $125 \mathrm{mg}$ ) administered over an average duration of about one year [13]. This same group later published a retrospective chart review that included 15 non-malignant head and neck pain patients who were treated with intrathecal bupivacaine monotherapy for an average of 53 days. These patients with severe head and neck pain had significant analgesia and decreased opioid requirements with mean intrathecal bupivacaine doses of 10.4 to $58.7 \mathrm{mg} /$ day [14]. A final study from 1996 also reported the benefit of intrathecal bupivacaine monotherapy in four non-cancer patients with head and neck pain [15]. The daily doses of intrathecal bupivacaine used in these monotherapy studies is significantly higher than the doses used in our patients, with our highest maximum dose being only $9 \mathrm{mg} /$ day. In these studies, the relative short duration of intrathecal monotherapy, the narrow and small patient 
populations, and the wide range of doses used makes it difficult to draw substantial conclusions. Questions regarding the dosing, long term efficacy, and benefit of intrathecal bupivacaine remain unanswered.

There does not appear to be any additional literature describing the use of bupivacaine as the sole intrathecal medication for non-cancer pain. Still, there are some interesting points to consider. Given that our patients were primarily treated for neuropathic pain, the inability to achieve effective pain relief despite increasing opioid doses is consistent with intrathecal opioids being less effective for neuropathic pain $[2,8]$. This premise is based on the fact that opioids primarily act at the dorsal horn in the spinal cord to interrupt nociceptive pain transmission, and their effectiveness in treating neuropathic pain, especially on a long-term basis, is less clear [16]. Three of our four patients received intrathecal opioids and failed the therapy, with one patient having never received intrathecal opioids.

Neuropathic pain patients are likely to be treated for a long duration, increasing their risk of succumbing to the vicious cycle of opioid tolerance and dose escalation that might otherwise be avoided altogether. With new evidence supporting the benefit of opioid discontinuation through interdisciplinary pain rehabilitation programs, nonmalignant chronic pain patients are able to improve functional status, pain severity, mental health, and quality of life by stopping all opioid medications [17]. This applies to our first and second patients who were able to discontinue their opioid use with overall benefit. The first patient completed such a program successfully. The second patient suffered from several known opioid side effects and was subsequently able to improve her functional status and quality of life through her own motivation to wean and discontinue oral and intrathecal opioids.

While opioids and ziconotide continue to be first line for intrathecal solutions, both agents have common and serious side effects. Ziconotide is further limited by its high cost. Though not directly applicable to intrathecal opioids, oral opioids are not recommended as the first line treatment of neuropathic pain, and oral opioids are increasingly being scrutinized for their lack of benefit in nonmalignant chronic pain $[18,19]$. One small study has even suggested increased mortality in non-cancer pain patients who were started on intrathecal opioids, presumably due to opioid-induced respiratory complications [20]. Currently, there is a lack of evidence to support intrathecal bupivacaine monotherapy. Our patient cases and the literature, however, call into question the long-term benefit of opioids in these patients. Therefore, certain chronic pain patients, such as those presented here, might have had more successful clinical courses if bupivacaine, rather than opioids, were used as the first line medication.

This case series and prior relevant studies are of course quite limited in scope as the number of patients presented is very small. Our patients' clinical courses were reconstructed from progress notes with varying levels of detail, making it somewhat difficult to fully appreciate their individual responses to medication changes and dose adjustments. We do feel, however, that this case series provides some support for the use of intrathecal bupivacaine monotherapy in patients with chronic, neuropathic, non-malignant pain.

\section{Conclusion}

In conclusion, this case series presents four patients with chronic non-cancer pain with difficult clinical courses and prolonged periods of ineffective analgesia. These patients experienced intrathecal ziconotide and opioid treatment failures, and two experienced significant functional improvement with opioid discontinuation. They all ultimately underwent intrathecal therapy with bupivacaine as the sole agent. Bupivacaine monotherapy appears to have been overall effective in achieving adequate analgesia in three of the four patients. The evidence regarding the use of intrathecal bupivacaine monotherapy is exceedingly sparse. However, given the decreased effectiveness of opioids in treating neuropathic pain, the long duration of therapy that non-cancer pain patients will likely undergo, and the emerging scrutiny of opioid use in nonmalignant pain, these data suggest that pain physicians may consider intrathecal bupivacaine as monotherapy in certain patients who are either refractory to opioid and/or ziconotide therapy or intolerant to its side effects.

\section{Acknowledgements}

Doctors Hale, Casserly, and Cheng had full access to patient records (data) used in the study and take responsibility for the integrity of the data. Dr. Hale managed the literature searches and summaries of previous related work and wrote the first draft of the manuscript. Doctors Casserly and Cheng provided revision for intellectual content and final approval of the manuscript.

Conflict of Interest: All authors have no conflicts of interest to report. None of the authors of the manuscript received any remuneration. Further, the authors have not received any reimbursement or honorarium in any other manner.

\section{References}

1. Deer TR, Pope JE, Hayek SM (2017) The Polyanalgesic consensus conference (pacc): recommendations for intrathecal drug delivery: guidance for improving safety and mitigating risks. Neuromodulation 20: 155-176.

2. Turner JA, Sears JM, Loeser JD (2007) Programmable intrathecal opioid delivery systems for chronic noncancer pain: A systematic review of effectiveness and complications. Clin J Pain 2023: 180-195.

3. Ver Donck A, Vranken JH, Puylaert M, Hayek S, Mekhail N (2014) Intrathecal drug administration in chronic pain syndromes. Pain Practice 14: 461-476

4. Hayek SM, Veizi IE, Narouze SN, Mekhail N (2011) Age-dependent intrathecal opioid escalation in chronic noncancer pain patients. Pain 12: 1179-1189.

5. Brookes ME, Eldabe S, Batterham A (2017) Ziconotide monotherapy: A systematic review of randomised controlled trials. Curr Neuropharmacol 15 217-231.

6. Rauck RL, Wallace MS, Leong MS (2006) A randomized, double-blind, placebo-controlled study of intrathecal ziconotide in adults with severe chronic pain. J Pain Symptom Manage 31: 393-406.

7. Kumar K, Bodani V, Bishop S, Tracey S (2009) Use of intrathecal bupivacaine in refractory chronic nonmalignant pain. Pain 10: 819-828.

8. Deer TR, Serafini M, Buchser E, Ferrante FM, Hassenbusch SJ (2002) Intrathecal bupivacaine for chronic pain: a review of current knowledge. Neuromodulation Technol Neural Interface 5: 196-207.

9. Veizi IE, Hayek SM, Narouze S, Pope JE, Mekhail N (2011) Combination of intrathecal opioids with bupivacaine attenuates opioid dose escalation in chronic noncancer pain patients. Pain 12: 1481-1489.

10. Deer TR, Caraway DL, Kim CK, Dempsey CD, Stewart CD (2002) Clinical experience with intrathecal bupivacaine in combination with opioid for the treatment of chronic pain related to failed back surgery syndrome and metastatic cancer pain of the spine. Spine J 2: 274-278.

11. Goucke CR, Dusci LJ, Van Leeuwen S, Fairclough D, llett KF (2010) Stability and tolerability of high concentrations of intrathecal bupivacaine and opioid mixtures in chronic noncancer pain: an open-label pilot study. Pain 11: 1612-1618.

12. Mcroberts WP (2016) Intrathecal bupivacaine monotherapy with a retrograde catheter for the management of complex regional pain syndrome of the lower extremity. Pain Physician 19:1087-1092.

13. Lundborg C, Dahm P, Nitescu P, Appelgren L, Curelaru I (1999) Clinical experience using intrathecal (IT) bupivacaine infusion in three patients with complex regional pain syndrome type I (CRPS-I). Acta Anaesthesiol Scand 43: 667-678.

14. Lundborg C, Dahm P, Nitescu P, Biber B (2009) High intrathecal bupivacaine for severe pain in the head and neck. Acta Anaesthesiol Scand. 
Citation: Hale J, Casserly E, Cheng J (2018) Intrathecal Bupivacaine as Monotherapy for Non-Malignant Chronic Pain: A Case Series. J Trauma Treat 6: 422. doi: $10.4172 / 2167-1222.1000422$

Page 5 of 5

15. Appelgren L, Janson M, Nitescu P, Curelaru I (1996) Continuous intracisternal and high cervical intrathecal bupivacaine analgesia in refractory head and neck pain. Anesthesiol 84: 256-272.

16. Beal BR, Wallace MS (2016) An overview of pharmacologic management of chronic pain. Med Clin North Am 100: 65-79.

17. Gilliam WP, Craner JR, Cunningham JL (2018) Longitudinal treatment outcomes for an interdisciplinary pain rehabilitation program: comparisons of subjective and objective outcomes based on opioid use status. J Pain.
18. O'Connor AB, Dworkin RH (2009) Treatment of neuropathic pain: An overview of recent guidelines. Am J Med 122: 22-32.

19. Krebs EE, Gravely A, Nugent S (2018) Effect of opioid vs nonopioid medications on pain-related function in patients with chronic back pain or hip or knee osteoarthritis pain. Jama.

20. Coffey RJ, Owens ML, Broste SK (2009) Mortality associated with implantation and management of intrathecal opioid drug infusion systems to treat noncancer pain. Anesthesiol 111: 881-891. 